\title{
Em defesa do corpo, em defesa da voz: a situação da performance vocal do poema e de sua investigação
}

Resumo: 0 principal objetivo deste artigo é entender a pouca importância dada à pesquisa e à produção crítica sobre a performance vocal nos estudos da poesia brasileira. Nesse sentido, é importante reconhecer que nosso contexto ainda está centrado numa visão de mundo que pode ser caracterizada como grafocêntrica, ou seja, ancorada na cultura letrada como valor. A consequência imediata disso é que não dispomos de ferramentas críticas e metodológicas adequadas para catalogar, arquivar, historiar e, em suma, produzir crítica acerca das performances produzidas por poetas contemporâneos brasileiros. Portanto, procuramos fundamentar, de um ponto de vista metodológico e histórico-crítico, as bases para se desenvolver o trabalho com a performance vocal de poemas como um campo específico. $\mathrm{O}$ artigo encerra com uma análise de obra, usando critérios adequados para uma mídia oral, como exemplo das possibilidades suscitadas pela pesquisa e reflexão crítica acerca da performance vocal de poemas no que diz respeito à compreensão da produção poética contemporânea

Palavras-chave: performance vocal, poesia contemporânea, poesia brasileira

Abstract: The main purpose of this article is to understand the lack of importance given to research and critical thinking regarding the vocal performance of poems in studies of Brazilian poetry. In this sense, it's important to recognize that our context is still centered in a world view that can be characterized as graphocentrism or scriptsm. The immediate consequence of such is that we lack proper tools to categorize, historicize, archive, and, in summon, critique vocal performances produced by Brazilian contemporary poets. Thus, it's important to establish that, from critical, methodological and historical points of view, the most important research on vocal performance is yet to be made. The article closes with an analysis of a vocal performance, using criteria adequate to an oral based medium, as an example of the possibilities entangled in the research and critical thinking of vocal performance to understand different aspects of contemporary poetry.

Keywords: vocal performance, contemporary poetry, Brazilian poetry 


\section{Introdução}

Para colocar, ou ver a partir de uma perspectiva melhor, a situação da performance vocal do poema na poesia contemporânea brasileira, é preciso compreender, ainda que não exaustivamente, a questão da performance vocal e do poema, vale dizer, de suas relações historicamente constituídas. Em diferentes momentos, os dispositivos a partir dos quais se concebe e se percebe o poético, ou o poema, apresentaram múltiplas formas e diversas materialidades. É no cruzamento entre tais formas e materialidades que se forja uma sugestão ainda que provisória do que uma determinada comunidade percebe como a manifestação "poema" ou "poesia", e que se estabelece diferenças entre valores estéticos, métodos de análise e de avaliação crítica. Assumir tal ponto de vista, pensando formas e materialidades, no plural, implica compreender a poesia não como fenômeno totalizante, mas como singularmente múltipla; é na relação entre seus múltiplos que novos modos de compreensão e de apreensão do poético surgem e possibilitam o desenrolar de sua história. Ou seja, de algum modo, quando falamos de poesia, a performance escrita estará em diálogo permanente com a performance vocal e outras performances cinéticas e visuais possíveis. A sugestão de que uma dessas formas/ materialidades possa se autonomizar e passar a responder como a instância verdadeira e final do poético é apenas uma construção histórica baseada em hierarquias provisórias estabelecidas socialmente entre as formas da cultura.

Talvez o primeiro problema sobre o qual deveríamos insistir, inicialmente, é: tem sentido apresentar conceitualmente como diferentes as ideias de performance vocal e de poema? Ao colocarmos a pergunta admitimos que é preciso de antemão abandonar a ideia de que a performance vocal é subsidiária de uma forma artística cuja identidade se encontra em outro suporte, seja pela hipótese de uma origem ou de uma forma final que se realiza, plenamente, em outra materialidade. O que é necessário esclarecer, portanto, é que, quando falamos da performance vocal do poema, ou de um poema, estamos falando do poema, tal como ele se apresenta em sua estrutura e materialidade a partir da voz que o performa. Não há nada na situação estética de um poema performado e escutado que precise procurar alhures as suas razões de ser, os seus elementos de fruição, as suas justificativas conceituais e estéticas. Evidentemente, do ponto de vista formal, as performances vocais e as performances escritas de um poema podem ser mais ou menos convergentes, mais ou menos compatíveis. Há dados audíveis que demandam diversas escolhas numa reinserção no contexto da escrita como há dados escritos que podem impor uma reinterpretação em outra materialidade. Nesse sentido, importa menos o que é precedente e mais o reconhecimento de que a existência do poema é múltipla, sendo passível de constantes e inúmeras transposições.

Não falaremos, portanto, de performance vocal do poema como algo a ser diferenciado do poema, mas como algo a ser diferenciado das outras performances do poema, escritas, visuais, etc. Compreendemos, assim, que o poema é suas performances, vale dizer, um evento múltiplo. Sobre o conceito, Bernstein (1998) pontua: 
Um poema compreendido como um evento performativo e não meramente como uma entidade textual recusa a originalidade do texto escrito em favor do "evento plural" da obra, para usar uma expressão de Andrew Benjamin. Isto é, a obra não é idêntica a nenhuma realização gráfica ou performática, nem pode ser equacionada em uma unidade totalizante dessas versões ou manifestações. O poema, visto nos termos de suas múltiplas performances ou de uma intertradutibilidade mútua, tem uma existência fundamentalmente plural. Isso ganha maior dramaticidade enunciativa quando instâncias da obra se revelam contraditórias ou incomensuráveis, mas também se aplica quando as versões diversas são comensuráveis. Falar do poema em performance é, portanto, superar a ideia do poema como um objeto linguístico fixo, estável, finito; é negar no poema sua essência e unidade. Logo, quando a performance enfatiza a presença material do poema, e do performer, ao mesmo tempo nega sua presença unitária, o que quer dizer sua unidade metafísica. (Bernstein 1998: 9 (tradução nossa))

Talvez o primeiro elemento a se destacar sobre a perspectiva sugerida pelo poeta e estudioso norte-americano seja a ênfase sobre a concepção da ideia de "obra". Se é verdade que a consideração do aspecto totalizante de qualquer obra sempre leva ao questionamento acerca de suas continuidades, descontinuidades e limites, ao nos colocarmos diante da poesia e dos poemas, o autor enfatiza que lidamos com transições e transposições que implicam outras materialidades. Por isso, o que fica sugerido é que a abordagem a que estamos acostumados, isto é, a que privilegia e busca estabilizar a performance escrita como objeto poético fixo, nega a realidade poética em prol da afirmação de uma unicidade impossível de ser apreendida de um ponto de vista de objetivo. Cumpriria, na contramão, reconhecer na proposta de uma "intertradubitilidade mútua" a sugestão de que todo gesto poético é transitivo, sendo articulado enquanto movimento de tal maneira que a "obra" não pode ser esgotada em uma de suas performances.

Reconhecer isso significa igualmente que as materialidades e formas influem - ainda que virtualmente - umas sobre as outras. Ou seja, pensar o múltiplo implica se colocar num terreno em que nenhuma das performances se esgota em si, uma vez que as outras possibilidades, embora diversas, se chamam, se interveem mutuamente, se afetam de maneira constante. Uma performance escrita é provocada pela materialidade da performance vocal (em potencial), como a performance vocal é atravessada pela forma escrita, e assim por diante. Todas as formas e todos os materiais de uma performance do poema se encontram em estado de abertura e como que à espera das outras performances que realizarão - de modo sempre inesgotável, inacabável - as outras formas e materiais possiveis.

Se, hoje, podemos colocar com essa clareza tal concepção de poesia e de poema, e de suas performances, cumpre reconhecer que, em diferentes contextos históricos, as diversas formas e materialidades não se apresentam de modo abstrato ou neutro ao 
horizonte de recepção. Antes, como afirmamos, elas foram e são alvo de uma constante ordenação e valoração, que busca estabelecer escalas de importância, mais ou menos ancoradas em elaborações culturais acerca da forma última, definitiva, ou verdadeira da poesia. O presente artigo pretende, portanto, aprofundar a reflexão sobre o atual estado da consideração do poema enquanto evento plural, demonstrando as especificidades da consideração da sua performance vocal. Desse modo, esperamos que fique demonstrado, por um lado, a importância de se repensar edições, catalogações, acervo e arquivos de obras poéticas, e por outro, a importância do estabelecimento sistemático de procedimentos críticos e metodológicos que demonstrem os elementos estéticos, a eficácia e materialidade da performance vocal poética. De alguma maneira, a tarefa que se coloca diante dos pesquisadores do assunto se assemelha à formulação de uma nova disciplina no campo da poética que permita uma melhor compreensão do fenômeno da poesia.

\section{Entre a letra e o som: perspectivas em disputa}

Em Da voz à letra, Sterzi (2012) apresenta o momento cultural de transição de uma poesia predominantemente oral para uma poesia predominantemente escrita a partir da análise da figura de Dante e da importância de seu trabalho para a formação de uma lírica moderna. De fato, a sua análise demonstra como a composição do soneto, em sua forma desenvolvida no modo de um silogismo, substitui por um ritmo ancorado no trabalho intelectual um ritmo ancorado no trabalho corporal - do paralelismo comum aos trovadores. Ainda assim, como o próprio autor assinala, essa passagem será marcada por um resto, virtual ou nostálgico, em que o elemento da voz e do som não se encontra efetivamente ausente. Nas suas palavras: “... o típico poema lírico moderno é sempre uma espécie de alegoria formal da passagem da poesia musical-vocal para a poesia escrita, e, sendo assim, carrega sempre em si a tensão entre um código musical e um código gráfico" (Sterzi 2012: 167). Ora, é justamente tal tensão que produz como que um campo em que as formas e materialidades performáticas do poema se movimentam. Nesse sentido, poderíamos dizer, verdadeiramente, que, se a lírica trovadoresca, o antecedente "superado" pela forma do soneto e pela lírica moderna, era predominantemente oral, isso não se dava sem que ela fosse atravessada, transformada, transposta para materiais escritos. Ou seja, se a oralidade permanece como nostalgia na lírica moderna, a escrita já se antecipa na lírica trovadoresca (como intuição, presságio?).

Então, um dos elementos importantes aqui, talvez, seja perguntar: dizer "poesia predominantemente oral" e "poesia predominantemente escrita" consiste no quê, exatamente? Primeiramente, precisamos descartar a possibilidade de supressão do modalizador. O que nosso parágrafo anterior já apontava é justamente que o poético acontece numa grade entre códigos e que sua existência histórica não pode ser encarada num modelo que se baseie numa construção oralidade-escrita simples, como pares de opostos. 
De modo geral, a concepção que pensa em termos dicotômicos a relação entre escrita e oralidade vem sendo questionada para todos os gêneros textuais há algum tempo. Como assinala Bagno (2011):

O linguista brasileiro Luiz Antônio Marchuschi, pioneiro dos estudos sobre língua falada entre nós, postula a existência de um espectro contínuo que vai do mais falado para o mais escrito, espectro atravessado pela variação estilística, que vai do gênero textual menos monitorado para o gênero textual mais monitorado. (Bagno 2011: 346 (grifos do autor))

Ora, a poesia pode ser encarada, então, como um gênero textual mais monitorado, isto é, um gênero cuja elaboração exige uma atenção formal grande (aqui, diferentemente da maioria dos casos, não estamos pensando "formal" apenas como padrão de organização socialmente compartilhado), que entretanto trabalha estilisticamente na passagem contínua do escrito ao oral e do oral ao escrito. Assim, mesmo nos casos de incursões poéticas de improviso, de performance da espontaneidade típica de textos menos monitorados, é mediante uma organização formal prévia de esquemas métricos, rimas e outros padrões, que se desenvolve o fenômeno poético. De modo complementar, tanto nos casos em que a oralidade busca suprimir a lógica escrita, quanto nos casos em que a visualidade busca suprimir a possibilidade de execução sonora, o próprio do poético é a insistência da escrita na oralidade, e da oralidade na escrita.

O que, efetivamente, parece se verificar é que, mesmo na lírica moderna, não temos apenas a sobrevivência da oralidade como nostalgia impressa na página, ou como virtualidade potencial. Há um conjunto de eventos em que o poema é apresentado, fruído, recebido, na sua performance vocal e que compõem a própria compreensibilidade do poema e sua apreensão. Esses eventos convivem harmoniosa ou problematicamente com os eventos de impressão, produção e reprodução escrita dos textos, mas em nenhum momento uns suplantam, substituem ou erradicam os outros. Logo, precisamos entender do que trata o advérbio usado acima, "predominantemente".

Em suma, se, como estamos vendo, não acontece historicamente de uma poesia escrita suprimir a oralidade, nem de uma poesia oral suprimir a escrita, isso tanto virtualmente, quanto concretamente em suas realizações performáticas, como se pode entender o que vem sendo designado por "predominância"?

Poderíamos nos perguntar se se trata de uma questão que deve ser entendida a partir de uma abordagem quantitativa. Seria possível supor - embora não tenhamos dados que tornem a apuração fácil ou definitiva - que por "poesia predominantemente escrita" queiramos dizer que há maior circulação de performances impressas e manuscritas que apresentações e gravações de performances vocais de poemas? Nesse sentido, uma primeira dificuldade é que talvez não possamos pensar numa totalização que inclua os diferentes gêneros poéticos nos diversos contextos históricos - a poesia satírica, por 
exemplo, em determinados contextos, se fez escassa em formas mais rastreáveis, como as impressas, e o mesmo se pode dizer de poemas pornográficos e licenciosos.

Em Poesia e polícia: redes de comunicação na Paris do século XVIII, Darnton (2014) se propõe a acompanhar as investigações da polícia francesa acerca da difusão de poemas que, por suas críticas e procedimentos satíricos, eram considerados crimes de lesa-majestade. O que o historiador descobre é, por um lado, uma rede de trocas de manuscritos entre estudantes, clérigos, funcionários de cartórios etc., e, por outro: “... um entretenimento popular em tavernas, bulevares e desembarcadouros, onde multidões se reuniam em torno de trovadores que tocavam rabeca ou realejo" (Darnton 2014: 73). Nesse caso, a pressão proibitiva de um modo de apresentar o poema faz com que as outras performances se tornem mais comuns e frequentes. E como o livro deixa claro, uma performance não exclui a outra, uma vez que, em alguns casos, os poemas eram copiados ou anotados a partir do ditado, isto é, de sua oralização. As instâncias de circulação apuradas revelam, na verdade, um trânsito constante entre oralidade e escrita, e sugerem um pensamento poético que combina as formas e os elementos de ambas materialidades.

Ainda, o passo é suficiente para indicar que qualquer esforço de quantificação é, de início, problemático, porque teria de se haver com o problema de como quantificar. Ou seja, se fôssemos adotar uma medida quantitativa, para apurar performances poéticas orais ou escritas, contaríamos pela produção ou pela recepção? Poderíamos ou deveríamos falar em "poesia predominantemente escrita" em contextos históricos em que a maior parte de recepção de textos poéticos se dá por meios de difusão de áudio, seja em canções transmitidas por via radiofônica, seja em gravações de discos de poesia falada?

A hipótese que gostaríamos de apresentar é a de que estamos, na verdade, falando de um valor socialmente compartilhado. Em texto, datado de março de 2009, publicado originalmente como postagem num blogue, o poeta Ricardo Domeneck (2009) apresenta o sugestivo título: “A voz contra a mão e esta contra a voz?". Nele, o autor começa problematizando o que denomina um hábito ocidental, a saber, o procedimento epistemológico de abordar os fenômenos a partir de uma categorização que opera por redução a um sistema de pares de opostos. Justamente, no caso, o que ele pretende, de modo análogo ao da linha adotada por linguistas mencionada anteriormente, é questionar o operativo dual que institui como par de opostos as instâncias da oralidade e da escrita. Nesse sentido, o texto recupera alguns dos traços associados a cada um dos termos na construção da dicotomia: o "oral", por um lado, seria visto como retórico e discursivo, e por outro, como espontâneo e natural. Na sequência, o poeta vai questionar todas essas atribuições ao demonstrar que as práticas poéticas orais demandam tanta elaboração quanto as escritas, e que há poéticas orais que não poderiam ser caracterizadas como discursivas. Paralelamente, o texto propõe que é precipitada a associação entre discursividade e imprecisão ou anemia estéticas. Ou seja, diante do 
que julga uma armadilha, a saber, a oposição oralidade-escrita, o poeta propõe como forma de desarmá-la um percurso duplo: por um lado, demonstra que a caracterização de "oralidade" e "escrita" são imprecisas e apostam em traços contingentes, por outro, questiona o valor estético que comumente está associado a esses traços.

Então, o autor faz referência a Paul Zumthor, justamente, para caracterizar o que pode ser entendido como hegemonia da escrita:

... é o que Paul Zumthor chamava de "hegemonia da escrita" em nossa cultura que faz com que todos os outros trabalhos poéticos recebam rótulos

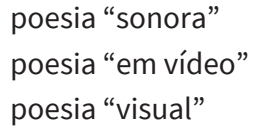

enquanto apenas a poesia "escrita" (ou poesia "literária") reserva-se o direito de não usar seu rótulo e auto-proclamar-se POESIA simplesmente.

É uma questão de ênfase (ou, se quisermos politizar a discussão, de hegemonia).

\section{$\S$}

Não há por que criar uma oposição entre trabalhos que investigam diferentes ângulos da poesia.

(Domeneck, disponível em: http://ricardo-domeneck.blogspot.com/2009/03/voz-contramao-e-esta-contra-voz.html, acesso em 22 abril. 2021)

O poeta cita a reflexão de Paul Zumthor para demonstrar como as formas de designação refletem uma certa ordenação de valores, uma certa hierarquia traduzida no estabelecimento dos nomes e das categorias. Desse modo, fica sugerido que enquanto "poesia" for o nome da modalidade escrita do poema estaremos diante de uma visão parcial do que é o fazer poético, que enfatiza hierarquicamente um de seus modos, um de seus aspectos. O que está subjacente à reflexão de Domeneck (2009) é a ideia de que não estamos tratando exclusivamente de valores de apreciação estética; antes, eles são subsidiários das construções ideológicas sobre cultura letrada e oralidade. Street (2014) demonstra como a crença na associação entre escrita e "distanciamento crítico", "racionalidade", "objetividade", disseminada entre sociedades de cultura ocidental, foi o germe inicial para a formação a ideologia de acordo com a qual a cultura letrada seria capaz de produzir progresso e elementos ligados às conquistas científicas obtidas a partir do lluminismo. A partir de estudos de letramento em relações transculturais, o 
autor pretende não só demonstrar a falsa equiparação entre letramento e progresso e seu cerne etnocêntrico, como também questionar a própria caracterização da cultura letrada como "objetiva", "crítica”, apontando como sua função ideológica está relacionada ao falseamento do uso político da escrita. De acordo com o autor, há tanto gêneros escritos, comumente desprezados na descrição do letramento, que não se caracterizam por apresentar "objetividade" e "distanciamento crítico" como há gêneros orais marcados pelo exercício da crítica e da racionalidade. Assim, a escrita como ponto de progresso de uma sociedade, como necessidade futura de qualquer desenvolvimento social, e poderíamos acrescentar, como valor estético do uso da linguagem, revela uma crença na superioridade ou na centralidade de certas sociedades e culturas.

Portanto, a princípio, podemos concluir que o que caracteriza a lírica moderna como "predominantemente escrita" é o valor cultural e social atribuído ao letramento è̀ cultura letrada, transposto para uma hierarquia estética de representação formal que destaca elementos ideologicamente associados à escrita. Mas talvez possamos ser mais precisos do que isso, uma vez que não acreditamos nem que o que seja uma lírica moderna está dado, e nem que estejamos diante de um processo consolidado e cristalizado na história. Compreendemos que, assim como os debates sociais e ideológicos que envolvem as relações entre letramento e oralidade no bojo da cultura, as disputas que envolvem o significado e os valores atribuídos a uma lírica moderna se repetem uma vez e de novo em cada contexto histórico, podendo muitas vezes assumir configurações distintas da representada pela passagem da voz à letra.

A título de exemplo do que estamos querendo dizer, de modo mais concreto, podemos apontar para alguns dos debates envolvidos na relação entre poesia, oralidade e escrita, nas gerações poéticas dos anos 1970 em diante no Brasil. De acordo com Moriconi:

Então o poeta dos anos 70 ainda se sentia, pra usar a expressão de Caetano, numa linha evolutiva, e o que vinha atrás dele, ou era o modernismo, como na poesia marginal, ou eram os concretos. Então ele tava se situando: eu venho depois desse pessoal, eu herdo esse pessoal, eu estou continuando essa tradição. Foi uma geração que sofreu o impacto da cultura de massa. Então foi uma geração problemática, não é? Porque fazer poesia em 67, em 68, com Caetano Veloso, com Chico Buarque, nos anos 70, não é fácil fazer poesia diante dessa avalanche de alta poesia que a própria música popular traz. Aí eu acho que isso realmente criou uma certa ruptura dentro da cultura letrada. (Moriconi 2009: 68 (grifos nossos))

Embora na fala de Moriconi (2009) sobre o assunto, a presença de Caetano se faça significativa como citação, é apenas no seu desenvolvimento que a ideia de uma influência da poesia cantada aparece com todo o seu peso, dentro de quadros assimilados como "cultura de massa", a partir da produção da indústria fonográfica, e como "música popular", etiqueta mercadológica apresentada como gênero a partir do 
contexto pós-bossa nova. A ideia construída pelo autor aponta para uma inserção na prática poética de disputas por poéticas distintas de disputas por poéticas a partir de um contexto marcadamente da cultura letrada. De modo que soa intempestivo, como que atravessando esse processo, aparece a influência de dois cancionistas, de maneira que parece pôr um problema, ou uma angústia. A frase “... como fazer poesia diante dessa avalanche de alta poesia que a própria música popular traz" é sintomática à medida em que revela uma certa relação na qual, talvez, possamos ver a lírica dividida em suas pulsões escrita e oral/cantada e seus movimentos conflitantes. Também é sintomática, pois claramente, como a continuidade do texto põe em evidência, "como fazer poesia" quer dizer "como fazer poesia escrita". A questão parece ser justamente aqui um confrontamento de um destino ou natureza pressuposta, a saber, da predominância da escrita, com a realidade de uma força estética (e econômica e política, já que a questão da cultura de massa está posta) que vai na sua contramão. Ou seja, pela afirmação de um potencial estético da poesia cantada e também pelo domínio hegemônico de uma forma comercial, a oralidade se apresenta como invasora do espaço da poesia escrita.

Acreditamos que a análise, embora abreviada, é suficiente para demonstrar a perspectiva de que a passagem de uma predominância oral para uma predominância escrita não se dá como etapa cumprida numa linha histórica. Antes, em nossa compreensão, as formas se atravessam e insistem continuamente umas sobre as outras a cada lance de um contexto, e cada artista ou cada geração histórica de artistas se vê de um modo ou de outro com questões que envolvem as diversas materialidades poéticas, aprofundando umas e mudando o destino de outras.

\section{Pesquisar a performance vocal do poema hoje: alguns desafios}

\subsection{As poéticas da canção}

O objetivo principal de nosso trabalho de escuta não se encontra no destino das performances vocais cantadas e da rica tradição da produção cancionista brasileira consolidada ao longo do século XX. Entretanto, é importante que façamos uma revisão de alguns dos lances interpretativos que buscam assimilar a sua força e o impacto na produção cultural e no horizonte de percepção e de recepção poéticos no Brasil. Treece (2004), em importante artigo panorâmico sobre as diferentes abordagens da forma cancional, estabelece uma divisão entre três linhagens desenvolvidas ao longo do século passado e ainda ativas hoje: a abordagem sociológica e antropológica da música; a abordagem literária com sugestões de história cultural; e a abordagem jornalística, biográfica ou baseada em entrevistas e relatos anedóticos. Na percepção do autor, as três encontram dificuldades em se aproximar dos elementos estéticos fundamentais da canção, uma vez que se distanciam da sua realização enquanto fenômeno musical/ sonoro. A primeira, ao se valer de categorias nacionais ou relativas a elementos étnicos e culturais dos grupos associados à produção de canções, se furtaria a uma análise formal do objeto. A segunda, ao enquadrar a canção dentro de uma tradição lírica, observaria 
a canção do ponto de vista de um quadro histórico em que, por motivos diversos, os aspectos melódicos foram desidratados, privilegiando exclusivamente o nível linguístico da composição. Um dos principais problemas desse enfoque, assinala o autor, é que, além de perder enlaçamentos constituidores de motivos fundamentais, reifica-se assim um padrão de juízo de valor cuja lógica é externa ao objeto cancional. Diferentes canções podem ser facilmente desprezadas, dessa maneira, porque suas letras não se sustentariam no contexto da leitura silenciosa da página escrita, procedimento que apresenta um flagrante equívoco de inadequação entre método e objeto. Por fim, a terceira abordagem, embora útil, no sentido de possibilitar discussões sobre contextos e condições de produção, nem sempre sugere dispositivos de análise das canções e uma maior compreensão sobre seus elementos de produção de sentido. Em contraste com esse cenário, Treece (2004) destaca a produção teórica de dois pesquisadores e artistas da área: José Miguel Wisnik e Luiz Tatit.

É curioso o conjunto de coincidências que cerca esses dois nomes. Além de ambos serem artistas e pesquisadores com publicações de importante valor acadêmico sobre o tema, talvez não seja ocioso sublinhar que também têm em comum a geração (apenas 03 anos separam as suas datas de nascimento) e o fato de serem de São Paulo e terem se formado e trabalhado na USP. Destacamos esses elementos, ausentes na análise de Treece (2004), porque no desdobramento da formulação teórica sobre as poéticas vocais eles podem se tornar relevantes, embora ainda seja cedo para se falar numa escola uspiana de pensamento sobre a canção, ou mesmo para determinar a extensão do elo entre acontecimentos culturais em que os autores se engajaram ao mesmo tempo em que desempenharam suas pesquisas (como a Vanguarda Paulistana da década de 1980).

Em 1979, Wisnik (2004a) publica um primeiro ensaio que trata do tema a que ele comumente vai se referir como "música popular brasileira". Trata-se de O Minuto e o Milênio, ou Por Favor, Professor, Uma Década de cada vez. O texto ficaria reconhecido menos pelas suas formulações, e mais pelo fato de o gesto, em sua área, constituir um ato inaugural, a saber, o da abordagem que confere dignidade estética a um material considerado produto para consumo, item da indústria cultural. Vinte anos após sua publicação, Silviano Santiago (apud Wisnik 2004a: 192) verá, ali, como marco, uma primeira crítica severa à separação entre erudito e popular, de modo a discutir o rebaixamento do último termo e promover a introdução da problemática dos Estudos Culturais no país. De fato, ao ler a canção a partir dos signos da "mistura" e do "caldeirão", o pesquisador uspiano explicita que ela combina elementos associados à cultura popular, ao que denomina "poesia culta" e ao mercado fonográfico, sem se reduzir à lógica de linhagens e oposições que estabelecem filiações, padronizações e rupturas dentro de cada um desses sistemas (cf. Wisnik 2004a: 178-179). Na consideração de Treece (2004), a recusa de tais enquadramentos é fundamental para um deslocamento com relação aos critérios das três abordagens que ele identifica como linhagem predominantes de leitura do objeto cancional no contexto brasileiro. 
Em 1994, Wisnik (2004b) realiza uma apresentação no seminário Pensamento brasileiro, cujo texto posteriormente é publicado internacionalmente e reunido, no Brasil, no volume Ao encontro da palavra cantada - poesia, música e voz, em 2001, ganhando o título de A Gaia Ciência: literatura e música popular no Brasil. A partir desse ensaio, como o título confirma, o autor estabelece uma associação entre o fazer cancionista do século XX brasileiro e os saberes da tradição provençal do século XII. Nesse sentido, Wisnik (2004b), ao abordar as relações entre a canção e a literatura brasileiras, não deixa de assumir a ideia de que estamos diante de um objeto poético-musical, consequentemente relacionável a uma certa tradição lírica. Treece (2004), todavia, esclarece que, em função dos conhecimentos musicológicos do autor, sua abordagem nunca isola em partes diferentes os signos da canção, trazendo para sua visada uma compreensão que contempla o elo fundamental entre a face linguística e a face melódica dos significantes. A mesma característica o autor reconhece no desenvolvimento da abordagem original de Luiz Tatit, cujo tratamento teórico e metodológico inaugura uma nova concepção da canção, de suas formas e de sua composição no país.

O caso é que, como fica explícito desde uma das primeiras publicações de Tatit (2014), redigida em 1983, o autor defende que, para entender o elo entre o que chamamos comumente de letra e melodia, não devemos pensar num somatório de elementos dos universos poético e musical. Com relação a isso, inclusive, ele faz questão de deixar explícito que, pela própria observação do trabalho de quem compõem canções, ou seja, pelo seu gesto criativo, pode-se demonstrar com alguma facilidade que estamos diante de alguém que se subtrai aos domínios estéticos da música e da literatura escrita. A chave para entender um elo poético-musical que não opera de acordo com princípios composicionais de um sistema nem de outro, de acordo com Tatit (2014) se encontra na oralidade. Ao analisar Queixa, de Caetano Veloso, o pesquisador indica a correspondência entre os contornos melódicos, em seu conjunto de descendências, e a entoação necessária das frases do texto, asseverativas. O que une melodia e palavra, portanto, num mesmo plano semiótico é a entoação. A partir disso, ele afirma:

... essa é uma das formas de pensar a relação letra/melodia em seus mecanismos de compatibilização. É pensar a canção dentro de seus próprios recursos, dentro daquilo que o compositor realmente (e naturalmente) concebeu. Trata-se, como se pode ver, de um procedimento diferente daquele que tenta avaliar uma canção pela qualidade dos versos tomados de um ponto de vista literário ou pela qualidade da melodia sob um enfoque musical. O que o compositor nos apresenta é uma proposta de integração e não uma proposta de justaposição de linguagens paralelas (Tatit 2014: 175)

Dentro de tal ponto de vista, pode-se compreender diferenças composicionais entre o canto lírico e o canto de compositores e intérpretes da canção, em termos de trabalho vocal/sonoro. Por ter como base de sua poética as unidades da entoação, 
consolidadas pelos falantes da língua, a canção vai sempre oscilar entre a precisão dos contornos melódicos e a encenação da fala. Com essa descoberta, o pesquisador desenvolveu, ao longo de quase quarenta anos de formulação acadêmica, um método de análise e interpretação ancorado na semiótica tensiva - a partir de Greimas e de Zilbeberg, principalmente - que permitiu: (a) reconhecer modos de produção de sentido como procedimentos específicos da canção; (b) descrever a relação entre tais elementos semióticos e tendências da indústria fonográfica e da recepção de canções (seu consumo como produto e sua compreensão como obra estética) no Brasil.

De acordo com Oliveira (2012), o método de Tatit distingue entre três modos básicos de estabilização melódica: a passionalização, a tematização e a figurativização. A estabilização é um processo que diz respeito à relação dialética entre a matéria falada e as formas do canto. Trata-se do trabalho através do qual os elementos erráticos e a tendência ao fragmentário da comunicação cotidiana falada vão ganhar padrões de repetição e regularidade sonoros a partir de quadros melódicos e musicais.

A estratégia da passionalização, caracterizada pela presença de maiores saltos melódicos, pelo aumento da duração das vogais, vai se combinar mais comumente a um texto linguístico com a abordagem de um conjunto de situações ou de realidades emocionais, relacionadas à perda do objeto amado, ou de um modo geral ao desencontro amoroso. Isso permite não apenas reconhecer um procedimento muito comum, como inclusive distinguir como o uso reiterado de tal recurso vai funcionar como elemento da caracterização de subgêneros cancionais - que devem ser compreendidos, ademais como quaisquer gêneros, não apenas como estruturas composicionais e formais, mas igualmente como elementos de organização da apreensão e da fruição do objeto estético. Sobre o assunto, sugerimos a observação da excelente pesquisa de Trotta (2011), acerca das relações entre "pagode romântico" e "samba de raiz", no final do século XX.

A tematização funcionaria como uma espécie de contraponto ao processo de passionalização, ou seja, se caracterizaria pela duração encurtada das vogais, enfatizando o movimento consonantal de modo que a progressão melódica ao invés de se caracterizar pelos saltos e pelo prolongamento, se caracteriza pela concentração e pela aceleração. De um modo geral, pode-se descrever seus contornos melódicos como a repetição de motivos que são continuamente repostos. Se o apelo das canções que se valem do procedimento da passionalização será à identificação emocional e ao aprofundamento psicológico, o das canções que utilizam sistematicamente a tematização se voltará para um destaque do ritmo e seu impacto sobre os movimentos do corpo. Do ponto de vista da matéria linguística, os textos que, de modo mais verossímil (considerando tal lógica de organização da oralidade), vão se aproximar dessa organização melódica são os que apresentarem situações, cenas do cotidiano, personagens situados num determinado instante, cujos contornos são reiterados na repetição constante dos motivos melódicos-poéticos. De acordo com Oliveira: "Vão ser canções moduladas pelo \fazer \, como o rock, o samba, a marcha e o axé" (Oliveira 2012: 139). A alternância entre 
gêneros caracterizados pela passionalização e gêneros caracterizados pela tematização caracterizou o funcionamento da indústria fonográfica no seu crescimento e por boa parte do século XX, com a dinâmica de lançamento de "canções de meio de ano", contrapostos ao lançamento de "canções para o carnaval".

Por fim, a figuratização diz respeito a um procedimento misto que permite o cruzamento múltiplo de elementos da fala e do canto, com a aproximação de procedimentos de estabilização melódica e retornos da desestabilização fragmentária da fala. Trata-se de procedimento típico de subgêneros como o "samba de breque", e que investem, do ponto de vista linguístico, na relação conversacional, na cena comunicativa que a canção cria, sem nunca se distanciar completamente da interação coloquial.

Como fica claro, nessa apresentação sumária da visão e da pesquisa de Tatit sobre a canção, o seu projeto de reinterpretação da forma cancional a partir dos elementos entoativos, resgatando-a simultaneamente da sua apropriação por padrões estéticos da literatura escrita e por padrões estéticos da música, tem um caráter global, envolvendo a produção, a circulação e a recepção crítica das obras. Não à toa, no texto de seu memorial, o autor sugere que essa visão pode transformar a base das relações de profissionalização (ele chega a incluir o projeto sonhado de uma formação acadêmica específica) e de produção. Talvez tais contornos justifiquem por que Tatit afirma no texto de conclusão de seu memorial: “... tenho uma sensação boa de que tudo apenas se inicia e uma sensação desconfortável de que tudo que aqui foi dito não chegou a acontecer, senão todos já saberiam" (Tatit 2014: 111).

Como atesta Oliveira (2012), de um ponto de vista estritamente acadêmico, no que diz respeito à pesquisa sobre a canção, o impacto de suas teorias já são perceptíveis, seja pela produção de seus orientandos, que aplicam o método semiótico na análise de arranjos, outras formas musicais etc., seja pela produção científica em geral acerca do assunto no país. O que o autor aponta como elemento crítico, entretanto, acerca da já volumosa obra de Tatit é a escolha pelo método da exemplaridade. Ou seja, o hábito de escolher de modo predominante para suas demonstrações obras do cancioneiro brasileiro que, a partir do momento pós-bossa nova, foram agrupadas num processo de consagração com a sigla MPB, sem que haja um debate metodológico que justifique mais detidamente as escolhas, pode criar espaço para a dúvida sobre se os procedimentos identificados seriam efetivamente típicos e construtivos da canção como tal, ou se apenas de um padrão cancional que se tornou mais prestigioso no Brasil. Efetivamente, como o próprio Oliveira (2012) reconhece, a única forma de sanar essas possíveis dúvidas é utilizando a forma de análise em questão para ler objetos cancionais que não obtiveram o mesmo prestígio.

Para nós, entretanto, encerrando esse excurso acerca das poéticas da canção, é importante destacar o quanto o deslocamento da atenção para os elementos entoativos da fala possibilitaram uma outra compreensão acerca de uma determinada prática artística. De fato, a percepção de determinadas singularidades das canções só foi 
possível com o abandono dos quadros da literatura escrita e da música, que acabavam por reduzir seu escopo, perdendo muitas vezes elementos fundamentais. Nesse sentido, acreditamos que a observação sistemática das performances vocais de poemas, em sua modalidade falada, podem trazer novos elementos para a compreensão do papel da oralidade na produção poética, e para a própria visão que temos do que seja poesia.

\subsection{Caminhos para a análise da performance vocal do poema}

A pesquisa e análise da performance vocal do poema, em sua modalidade falada, ainda está por ser feita no Brasil. Há uma série de indícios dessa realidade: não dispomos hoje de arquivos completos - catálogos, listas bibliográficas, etc. - dos registros de performances vocais feitos por nossos poetas; não temos sugestões de transformações de estilo e de formas composicionais ao longo da história (se alguém supõe que se apresentam oralmente poemas hoje do mesmo modo que no século XIX, ou no início, ou em meados do século XX, está justificadamente enganado uma vez que não dispomos das demonstrações das transformações ou mesmo da história dessas mudanças); não encontramos, afinal, ferramentas metodológicas pertinentes consolidadas para análise das especificidades da performance vocal de poemas.

Poderíamos dizer, inclusive, que sequer dispomos de uma compreensão apurada do estatuto textual específico do nosso objeto. No caso da performance vocal falada do poema, assim como no caso dos cancionistas e de outras modalidades de performance aproximadas, como a de atores apresentando uma peça, podemos dizer que temos um texto de expressão oral e de composição mista, tanto oral como escrita. Ou seja, diferentemente de textos com aspectos intrínsecos da fala, como a hesitação e a repetição em função da simultaneidade de produção e planejamento textuais, a performance falada apresenta planejamento anterior - que pode envolver ou não o uso de materiais escritos. Mesmo nos casos de improvisos, eles só acontecem mediante um conjunto de recursos previamente estabelecido e estudado pelo performer, a partir do qual a composição encaixa novos segmentos verbais em formas mais ou menos previsíveis. Portanto, os elementos normalmente associados à gramática da língua falada - como correção, parafraseamento, construção de tópico discursivo, dentre outros - só aparecerão na medida em que forem um recurso e um tema expressivo da composição. Note-se, por exemplo, o uso elaborado da hesitação na performance vocal de Renato Negrão Odisseiavácuo (cf. trechos disponíveis em <https://www.youtube.com/watch?v=y6wMbHsOJgQ>, acesso em 03 jul. 2021). No caso, ouvimos alongamentos vocálicos localizados sempre na última sílaba pronunciada em cada frase ou verso, quase sempre sílabas de itens funcionais. São reproduzidos, portanto, padrões que performatizam a hesitação, a partir de suas características reais como estratégia constitutiva da produção do texto falado, segundo a caracterização de Marcuschi (2015). Devemos enfatizar, todavia, que em tal performance a hesitação tem como objetivo a produção de um discurso lacunar, figuração do "vácuo" que intitula o poema. Não se trata, então, de um recurso de formulação 
prospectiva. Antes, é uma estratégia ensaiada para melhor caracterizar o alvo da sátira.

Tal realidade - da constituição da performance como texto misto com combinação de elementos orais e escritos - pode levar a crer que a performance vocal do poema não apresenta especificidade ou relevância estética, constituindo uma mera transposição textual de uma mídia para outra. É uma posição ingênua por dois motivos: primeiro, porque a mudança de meio expressivo implica novas camadas de trabalho estético - o som traz consigo um universo de dados como volume, timbre, altura, fraseado rítmico, duração vocálica, dentre outros; segundo, porque, como acreditamos já ter apontado, a performance vocal não está excluída da composição do poema, sendo determinante inclusive para várias escolhas lexicais e morfossintáticas. Desse modo, reafirmamos que o que estamos propondo é que, ao criar um poema, não se cria um objeto textual específico oral ou escrito ou visual ou escultural, mas um campo performativo em que as diferentes materialidades influem sobre si.

De fato, com relação ao primeiro aspecto, inclusive, veremos que é ilusório acreditar que a performance vocal vai apenas atualizar o código escrito até no que diz respeito a elementos considerados presumíveis - por exemplo, nos cortes e pausas de fraseado. A situação, cujo esclarecimento é a função principal deste artigo, é que não dispomos de material metodológico e crítico para abordar a especificidade da performance vocal falada do poema, o que, de acordo com nossa hipótese, leva a uma compreensão circunscrita do fenômeno poético a uma de suas possibilidades materiais, a uma de suas atualizações formais. Portanto, uma compreensão limitada.

O crítico que se coloca diante da obra de um poeta que apresenta um trabalho com performance vocal consolidado e enfatiza tal aspecto em sua reflexão sobre a linguagem poética, normalmente, opta por uma de duas opções: (a) descrever, histórica mas também situacional ou discursivamente, os contextos em que as performances vocais mais públicas e mais significativas aconteceram; (b) reafirmar a importância da oralidade para a compreensão da obra do autor. As análises, entretanto, se voltam para as apreciações morfológicas, gramaticais e até fonológicas do texto escrito dos poemas, uma vez que esse é o instrumental analítico que a pesquisa na área de Letras consolidou. Nossa posição é a de que, se, como apontamos, uma performance vocal também se faz de volume, timbre, altura, fraseado rítmico, duração vocálica, é preciso saber voltar a escuta para tais elementos. É preciso saber descrevê-los em sua especificidade, é preciso saber traçar os panoramas dos usos e recuperar as linhagens históricas dos procedimentos com tais materialidades.

Ora, o que está dito sobre a crítica, com pequenas adaptações, pode ser dito sobre a curadoria, o arquivo e a conservação dos materiais gravados em áudio e em audiovisual dos poetas brasileiros ao longo do século XX e início do XXI. A situação é de total dispersão de um material que é tratado, quando muito, como uma curiosidade, um dado extraliterário com menor relevância para a compreensão das obras poéticas que arquivos escritos, correspondência e entrevistas. 
Igualmente, a construção de um percurso histórico inexiste, mesmo que disponhamos de evidências, a partir de fontes secundárias, de grandes transformações, por exemplo, entre o século XIX e as primeiras décadas do século XX. Byrne (2014), falando da música, aponta justamente para como a criação do fonógrafo cria um novo espaço no interior dos ambientes privados. Passa-se a esperar que as mesmas composições possam circular por espaços sociais e acústicos completamente distintos - o das salas e espaços privados munidos de aparelhagem radiofônica e o das casas de espetáculo. Tal transformação social se dá em consonância com um conjunto de transformações estéticas e formais nos modos da produção artística musical. Fenômeno semelhante se dará com a performance vocal do poema falado que descobre novos traços a partir do trabalho da "coloquialidade" no modernismo.

Para que o movimento desse artigo não redunde, entretanto, na observação lamentosa de um ambiente inexpugnável, pretendemos encerrar com um exercício analítico que tem como objetivo ser um pontapé inicial, ou ao menos, o apontamento de uma possível trilha a ser aberta na consideração crítica da performance vocal do poema. Devemos enfatizar que se trata de exercício a título de exemplo do que acreditamos que pode ser desenvolvido num sentido diferente do que caracteriza o estado de coisas comentado. Para tal, vamos nos valer da obra Estereofonia, de Marília Garcia, a partir de seu registro na revista-disco de poesia Bliss não tem bis.

A faixa em questão é a nona do disco 2 do projeto artístico, que registra, além da poeta, performances vocais de Antonio Cicero, Angélica Freitas, Ricardo Aleixo, dentre outros. Apresentando um total de dois minutos e 15 segundos de duração, ela conta com, além da performance vocal da poeta, a inserção de efeitos de eco e reverberação em alguns versos, uma linha melódica dedilhada no violão - pela própria poeta - dando corpo sonoro à citação da canção "Bandeira Branca”, de Laércio Alves e Max Nunes, e a inserção da voz do também poeta Leonardo Gandolfi, nos trechos dialogados do texto poético. Há, de modo bastante evidente, portanto, um conjunto rico de superposição de diversas camadas sonoras e significativas a serem exploradas. Afinal, como dito, além dos dados de elaboração já mencionados, temos as palavras em que ocorrem prolongamentos vocálicos, a escolha do timbre, e os inúmeros elementos que compõem a performance. Para a finalidade deste artigo, vamos nos ater à observação do fraseado rítmico, e para sermos efetivamente precisos, ao uso das pausas na organização desse fraseado.

Ao falar de "fraseado", nos referimos às divisões operadas seccionando conjuntos de massa sonora preenchida, e intervalos, maiores ou menores, de silêncio. Na produção do texto oral cotidiano, tal divisão se opera a partir da organização sintática do texto, e a partir da necessidade de elaboração ou reelaboração discursivas. No caso das performances vocais de canções, ela estabelece a inteligibilidade da linha melódica, e uma lógica de retorno e previsibilidade na relação entre tempos fortes e fracos. No caso das performances vocais de poemas, muitos esperam que a realização oral apenas 
opere uma transposição de dados gramaticais e de disposição gráfica - as pausas acompanhando exclusivamente as indicações sintáticas e os cortes de verso. De fato, há uma tradição poética em que tal prática parece ter tido peso singular, estruturando uma certa concepção de verso. Entretanto, à medida que a poesia moderna trabalhou e trabalha noções de verso e de ritmo distintos, é notável que as performances vocais integrem tais transformações.

Para permitir uma melhor compreensão do nosso trabalho, apresentamos abaixo uma transcrição na qual está disposto o texto do poema performado nos moldes da forma teatral, com a marcação das pausas efetivamente realizadas em rubricas e indicação das quebras de versos e dos limites entre as estrofes por meio de barras inclinadas. Quanto aos limites de versos e de estrofes, utilizamos a versão escrita publicada no encarte da revista-disco. Há uma outra versão do poema publicada em livro de publicação em data posterior, mas que inclui alterações maiores (mudanças de palavras, versos, etc.), que, por ora, dificultariam a análise pontual que almejamos.

estereofonia (pausa)// nunca falei tão sério/ (pausa) disse e olhei pra cima (pausa) seu rosto no/ meio das gotas (pausa) guarda-chuva/ preto como uma moldura redonda (pausa) e você parado/ (pausa) cantando virado para o vidro do carro sem ouvir/ mais nada/ (pausa) e a voz/ livro sonoro/ (pausa) e a voz cantando no meio da chuva/ (pausa) não posso mais (pausa) virado para o vidro do carro/ isso podia ser você (pausa) mas o caminho mais rápido de um/ ponto a outro ele diz/ (pausa) e eu olhei pra cima// (pausa) ele arrependido conta/ (pausa) perto dali uma mulher entrou no/ bar (pausa) ela tinha o seu nome/ (pausa) y el chico disse (pausa) no no es verdade/ (pausa) você estava lá?/ (pausa) ela se chamava doris salcedo// (pausa) podia ter vindo de outro lugar (pausa) olhando pra longe/ (pausa) os cílios partidos/ (pausa) e a voz cantando no meio da chuva/ (pausa) não posso mais (pausa) mas o caminho mais rápido me diz (pausa) e/ eu olho pra cima (pausa) e lembro da cor malva/ (pausa) e dele dizendo que é quase/ malva (pausa) tem um pingo tornando malva/ (pausa) mas a única cor que lembro (pausa) era o nublado daquele dia/ (pausa) a única cor que lembro (pausa) era o/ chumbo daquela vez (pausa) e eu olho pra cima você descia/ as escadas/ (pausa) no último degrau já sabe/ (pausa) cada curva/ contém quinze passos (pausa) ou era só um poema/ essa viagem muda em zigue-zague atravessando/ o asfalto algarismos de velocidade e raios de esquecimento/ (pausa) sendo assim seu poema tem quinze passos (pausa) conta os/ metros/ enquanto vai dizendo o poema caminhando (pausa) mas/ daquele dia vejo só o chumbo e a voz/ no vidro do carro/ (pausa) depois levanto um braço (pausa) guarda-chuva preto/ (pausa) moldura para descongelar cada um dos vinte e quatro degraus/ (pausa) pra descongelar a ordem do verso seguinte/ (pausa) panorâmica golpe e locutor// (pausa) você vai sempre pelo som?/ (pausa) - que som? (Garcia 2013)

O primeiro elemento que chama a atenção é a pontuação do discurso com uma quantidade significativa de pausas, impondo um ritmo bem mais cadenciado e 
fragmentado que o da fala cotidiana. Ou seja, enquanto a fala cotidiana privilegiaria a continuidade e o preenchimento dos vazios, de modo a inserir pausas em posições sintáticas específicas (ou após conclusão de frases, ou em espaços entre sintagmas em função do seu planejamento ou da ênfase específica que se queira dar a eles), a performance vocal falada do poema quebra o discurso em unidades menores chamando a atenção para divisões que tem como critério o estabelecimento de padrões rítmicos. Entretanto, isso não quer dizer que não haja uma ligação entre a organização rítmica e a organização lógica do texto. De fato, no primeiro conjunto de frases, em que se desenha a composição de uma cena, a pausa parece funcionar como um corte, que anuncia ao ouvinte a inserção de novos elementos ou o deslocamento de uma imagem mais ampla para um detalhe, uma parte que se quer enfatizar.

A fragmentação rítmica reencena, portanto, no plano da expressão sonora, uma fragmentação discursiva, uma vez que, em meio a uma cena de chuva e de interlocutores cujas vozes parecem se perder numa superposição polifônica, o que sobressai é uma diferença (de aceleração, de velocidade, do ritmo da atenção?), um desencontro. Com relação ao aspecto da estrutura polifônica do texto, há que se notar o conjunto de procedimentos discursivos para além da construção dialogada do texto. Isto é, não só o texto narra um diálogo entre uma primeira pessoa e uma segunda pessoa, como ele se encontra preenchido com intertextualidades ("cantando na chuva", a citação do verso "não posso mais" de Bandeira Branca, a menção à artista Doris Salcedo) e com um desdobramento diglóssico relacionado.

Dentro de tal perspectiva, podemos dizer que temos um movimento inicial composto pela progressão com unidades de massa sonora próxima, ou com a alternância de unidades de massa sonora próxima e unidades de massa sonora dobrada ou aumentada, numa fixação rítmica que poderíamos caracterizar como fragmentária, mas não como aleatória nem como irregular, por inexatidão. Todavia, tal construção é interrompida na segunda metade da peça pela irrupção de uma torrente frasal que, efetivamente, rompe com a organização fragmentária, fazendo o ritmo da fala e da frase que quer se dizer inteira jorrar, carregando num fluxo de intensidade o que até então era uma construção de segmentos articulados. Estamos falando, esperamos que esteja claro, do surgimento do segmento sonoro "ou era só um poema/ essa viagem muda em ziguezague atravessando/ o asfalto algarismos de velocidade e raios de esquecimento/". Do ponto de vista da duração e da quantidade de palavras, da composição da massa sonora, oposta à interrupção das pausas, é sem dúvida nenhuma desproporcionalmente maior que qualquer outro segmento isolado da performance. Dessa maneira, a poeta destaca o trecho como pedaço chave, ou elemento fundamental que introduz uma alteração na performance, trazendo o movimento final que terminará no menor segmento isolado, formado pelo verso de encerramento de apenas duas sílabas, destacado como frase interrogativa, que se segue a uma frase interrogativa anterior, num final ascendente, em que uma questão vai de encontro à outra, em suspenso. 
Como talvez não seja difícil de notar, o segmento destacado não é destituído de sentido. Pelo contrário, trata-se da inserção de um discurso metalinguístico que reinterpreta toda a cena anterior, numa indagação que nos põe entre a memória da experiência e a linguagem, por um lado, e entre as vozes das performances, das gravações fonográficas e o silêncio do código escrito, por outro. A partir daí, a questão do ritmo e da medida se colocam numa estrutura ambígua (pela menção com duplo sentido a "metros", ambiguidade acentuada se lembrarmos a semelhança de campo semântico entre passo e pé), em que a estrutura do poema e o movimento do corpo que diz o poema se embaralham, se superpõem num mesmo acontecimento.

Ao final, a pergunta pelo som, em sua relação clara com a espacialização, com a orientação do movimento, deixa em suspenso a definição. Ao nosso ver, o que se busca sustentar é justamente uma oscilação entre os caminhos apresentados, o poema é tanto a memória da experiência quanto a sua reelaboração pela linguagem dos versos, tanto a reprodução, gravação de sons a partir de uma reconstituição espacial das fontes sonoras (aludida pelo título) quanto o esquecimento no código de algarismos, o poema é, enfim, tanto os metros dos seus versos quanto os metros percorridos por um corpo que fala em voz alta. Uma impressão que se poderia registrar é a de que Marília Garcia, notadamente a partir de certo ponto de sua obra, sugere uma concepção de ritmo de poema que inclui essa oscilação entre suas materialidades, entre suas performances.

\section{3. À guisa de conclusão}

O que esperamos ter ficado evidente, a partir do exercício de análise, é que a performance vocal dos poemas é uma dimensão de exercício de criação estética, que permite trazer, a partir da análise de seus elementos específicos, outras reflexões e leituras que aprofundam a compreensão do poema em suas diferentes formas e materialidades. A partir disso, sustenta-se a ideia de importância de uma transformação de atitudes, conferindo dignidade e relevância cultural a esse fazer poético, de modo a não só desenvolver aparato crítico e metodológico para leituras e análises diversas, como também discutir de modo mais amplo a conservação, a curadoria e o arquivamento de tais materiais. Na perspectiva exposta, o principal elemento que nos leva à manutenção de um contexto em que as performances vocais dos poemas são tratadas como irrelevantes ou insignificantes de um ponto de vista teórico e cultural é a hegemonia de uma concepção grafocentrada que supõe na forma escrita o destino ou a verdade da criação poética. Tal concepção, como visto, não deixa de se relacionar a outras estruturas e relações de poder fundantes de discursos da modernidade nas sociedades ocidentais. Se não sustentamos a ilusão de uma proposta que supere seus impasses, julgamos que é preciso descongelar os quadros de leitura e interpretação para melhor nos aproximarmos dos movimentos de nossas cenas poéticas e de criação artística. 
NOTA

* Lucas de Mello Cabral e Matos é professor de Língua Portuguesa e de Literatura Brasileira no Instituto de Aplicação Fernando Rodrigues da Silveira/CAp-UERJ, na Universidade do Estado do Rio de Janeiro (UERJ) e artista. Desenvolve pesquisa sobre poesia e performance vocal, tanto na área da produção acadêmica quanto na produção artística. Publicou os livros de poemas Três semblantes (7letras), 1989 (7letras) e Dentro da barriga da besta (LunaParque). Participou da exposição Rejuvenesça: poesia expandida hoje com instalação de áudio de poesia. Integra o coletivo poético Blixx.

\section{BIBLIOGRAFIA}

Bagno, Marcos (2011), Gramática pedagógica do português brasileiro. São Paulo, Parábola Editorial.

Bernstein, Charles (1998), "Introduction”, in Berstein, Charles (org.), Close Listening: poetry and the performed word. New York, Oxford University Press.

Byrne, David (2014), Como funciona a música, tradução de Otávio Albuquerque. Barueri, SP, Amarilys.

Darton, Robert (2014), Poesia e polícia: redes de comunicação na Paris do século XVIII. São Paulo, Companhia das Letras.

Domeneck, Ricardo (2009), A voz contra a mão e esta contra a voz?, Disponível em: < http://ricardo-domeneck.blogspot.com/2009/03/voz-contra-mao-e-esta-contravoz.html>. Acesso em: 22 abril. 2021.

Garcia, Marília (2013), Estereofonia. Bliss não tem bis: revista-disco de poesia, organização de Lucas Matos, Clarissa Freitas, Márcio Junqueira e Thiago Gallego. Rio de Janeiro, edição dos organizadores. Apoio: UERJ. Faixa 07, cd 02 (áudio).

Marcuschi, Luiz Antônio (2015), "Hesitação", in Jubran, Clélia Spinardi, A construção do texto falado. São Paulo, Contexto.

Moriconi, Ítalo (2009), “Entrevista com Ítalo Moriconi” [por Márcio Junqueira, Lucas Matos e Luciana di Leone], Bliss: revista de poesia, organização de Lucas Matos, Clarissa Freitas e Márcio Junqueira, Rio de Janeiro, 7Letras: 55-77.

Negrão, Renato (2019), Renato Negrão lança Odisseia-vácuo. (Entrevista). Disponível em < https://www.youtube.com/watch?v=y6wMbHsOJgQ > Acesso em: 03 julho 2021. 
Oliveira, Acauam Silvério (2012), O modelo semiótico de Luiz Tatit e suas implicações na análise da canção popular no Brasil: algumas considerações iniciais. LINGUAGEM. ESTUDOS E PESQUISAS (UFG), v. 16: 131-147.

Sterzi, Eduardo (2012), Da voz à letra. Alea: Estudos Neolatinos, v. 14/2: 165-179,

Street, Brian (2014), Letramentos sociais: abordagens críticas do letramento no desenvolvimento, na etnografia e na educação. São Paulo, Parábola Editorial.

Tatit, Luiz (2014), Todos entoam: Ensaios, Conversas e Lembranças. 2 ed. Cotia, SP, Ateliê Editorial.

Treece, David (2004), Melodia, Texto e O Cancionista, de Luiz Tatit: novos rumos nos estudos da música popular brasileira. Teresa: Revista de Literatura Brasileira, v. 4/5: 332-350.

Trotta, Felipe (2011), O samba e suas fronteiras: "pagode romântico" e "samba de raiz" nos anos 1990. Rio de Janeiro, Editora UFRJ.

Wisnik, José Miguel (2004ª), O Minuto e o Milênio ou Por Favor, Professor, Uma Década de Cada Vez, in Wisnik, José Miguel, Sem receita. São Paulo, Publifolha.

-- (2004b), A Gaia Ciência: Literatura e Música Popular no Brasil, in Wisnik, José Miguel, Sem receita. São Paulo, Publifolha. 